\title{
Un balance de los estudios sobre las Organizaciones Politico-Militares argentinas
}

\author{
Gabriel Rot
}

Centro de Documentación de las Organizaciones Político-Militares Argentinas El Topo Blindado gabrielrot@gmail.com

Se ha escrito y mucho acerca de la producción sobre las décadas del 60 y del 70 en los últimos cuarenta años. En este recorrido puede reconocerse una primera etapa representada particularmente por las pioneras críticas al accionar armado aparecidas en el exilio, muy particularmente en la revista Controversia, y por trabajos como el de Carlos Alberto Brocato (1985). En los años 80 y 90 destacan las llamadas "historias militantes", buena parte de ellas testimoniales, y aproximadamente desde el año 2000, finalmente, una nueva etapa caracterizada por el tratamiento investigativo riguroso, profesionalizado, sostenido por una amplia variedad de fuentes documentales.

Así las cosas, lo producido ha logrado satisfacer, aunque con límites precisos, la reconstrucción organizacional de las dos principales organizaciones político-militares -Montoneros y el Partido Revolucionario de los Trabajadores-Ejército Revolucionario del Pueblo (PRT-ERP)- ${ }^{1}$ como así también de unas pocas organizaciones más: los pioneros Ejército Guerrillero del Pueblo (Rot, 2000 y 2010; Ávalos, 2005) y Uturuncos (Salas, 2003), las Fuerzas Armadas de Liberación (Rot, 2003-2004; Hendler, 2010; Grenat, 2010), los grupos ligados a Cristianismo y Revolución (Morello, 2003; Campos, 2016; Lanusse, 2007), el Grupo Obrero Revolucionario (Cortina Orero, 2011), las fracciones del PRT: "22 de Agosto" (Weisz, 2005) y "Roja" (Cormick, 2012), las Fuerzas Armadas Peronistas (Duhalde y Pérez, 2002; Luvecce, 1993), la Organización

1. Son numerosas las obras dedicadas a Montoneros y al PRT-ERP. Dejamos constancia aquí de unas pocas, pero ineludibles lecturas. Para Montoneros: Richard Gillespie (1987), Juan Gasparini, Lucas Lanusse (2007), José Amorin, Ernesto Salas (2003) y los testimonios de Roberto Perdía, Rodolfo Walsh y Juan Gelman. Para el PRT: Pablo Pozzi y Alejandro Schneider (2000), Luis Mattini, Daniel De Santis y Rolo Diez (2010).

(Archivos, año V, no 9, septiembre de 2016, pp. 33-53) 
Comunista Poder Obrero (Castro e Iturbure, 2004; AA.VV., 2009; Cormick, 2015), la Guerrilla del Ejército Libertador (Rot y Campos, 2010), el Partido Comunista Marxista Leninista (Celentano, 2005), las Fuerzas Armadas Revolucionarias (Caviasca, 2006; González Canosa, 2012) y las Fuerzas Armadas de la Revolución Nacional de Bengochea (Nicanoff y Castellano, 2006).

A estas se le ha sumado auspiciosamente el trabajo sobre corrientes no armadas que han debatido el problema de la acción guerrillera, como el comunismo y el trotskismo -reflejado en los trabajos de Campione (1996, 2005, 2007), Rot (2006), Nadra (2012) y Casola (2015), para el primero y Mangiantini (2014), para el segundo- y los estudios de género que han tenido una importante expansión y atraviesan a diversas organizaciones (Martínez, 2009; Andújar, 2009; Noguera, 2013; Oberti, 2015, entre otras).

Parece mucho; no lo es si se tiene en cuenta el frondoso mapa de las Organizaciones Político-Militares (OPM), que suma unas 50 organizaciones que en los 60 y 70 asumieron como propia o bordearon la cuestión armada, las menos con alcance nacional, pero en algunos casos con una presencia provincial o regional que merece ser explorada, aunque hasta el momento esta cuestión no se ha establecido con firmeza en la historiografia especializada.

Pensemos, por ejemplo, en Córdoba, donde surgieron organizaciones locales como el Movimiento Revolucionario Argentino (MRA), el Comando Pampillón y la Columna Sabino Navarro, algunas con algún predicamento entre los trabajadores y el movimiento estudiantil. Lo mismo cuenta para Jujuy y Salta, donde operaron grupos anarquistas, como el Comando Bakunin, y el Ejército de Liberación del Norte, brazo armado del Frente Revolucionario Peronista (FRP), de los que se tienen escasas noticias, pero testimonios diversos le acreditan gran operatividad y cierto arraigo en sectores campesinos y barriales. La ausencia de estudios sobre estas organizaciones nos impide recuperar acciones y tradiciones de dos sectores de la militancia, como el anarquismo y un sector del peronismo revolucionario atravesado por la influencia marxista, que se mantuvo equidistante de las OPM peronistas y marxistas mayores. La carencia de estudios regionales tiene sus excepciones: el trabajo de Javier Salcedo (2011), sobre la zona de Moreno; los de Cristina Viano (2011) sobre la JP en Santa Fe y de Robles (2011) sobre la JP en La Plata; el de Laura Pascuali (2007) sobre el Comando Che Guevara en Santa Fe, y unos pocos artículos que publicó la revista Lucha Armada sobre la JP en Luján (2007) y el PRT en Mar del Plata (2008). Seguramente hay más, pero parece muy poco para una actuación guerrillera tan intensa como la desarrollada en nuestro país.

Paralelamente a este universo de producciones, ha surgido una 
tendencia "demonizadora", que constituye un fenómeno en alza. Las argumentaciones de la misma aparecen tempranamente en la revista Informaciones, que respondía a los servicios de inteligencia del Ejército en los años 70, y que Félix Luna, en prólogo a Gillespie (1987), va a recuperar una década más tarde, cuando defina la militancia setentista como "locura", una manera nada sutil de reconvertir la racionalidad política revolucionaria en un compendio de desvaríos adolescentes y sicopáticos, conceptualizaciones que Pablo Giussani supo hilvanar en Montoneros, la soberbia armada (1984).

Las mismas argumentaciones serán frecuentadas y reverdecidas por autores marcadamente anticomunistas como Juan Bautista Yofre (2006, 2007, 2009, 2010, 2014); Vicente Massot (2011, 2013); Carlos Manuel Acuña (2000); Guillermo Rojas (2001) y Ceferino Reato (2013), entre otros. Lo curioso es que el mismo eje referencial de irracionalidad política será utilizado por autores insospechados de esa tendencia, como Hugo Vezzetti (2009) y Laura Alcoba (2008), entendiendo y definiendo la militancia setentista en términos de "pulsión de muerte" y "seres arrebatados por la violencia", respectivamente.

A éstos se le les ha sumado una acotada pero ruidosa pléyade de ex militantes, tales los casos de Héctor Leis (2013) y Sergio Bufano (2004, 2007): el primero, ya fallecido, convertido en un auténtico paradigma de fe reconciliatoria; el segundo -que hiciera sus primeras armas criticas en el exilio centrando sus dardos contra el vanguardismo armado-, machacando pertinazmente en las descomposiciones de la praxis armada, lumpenizando y patologizando todo lo concerniente al pensamiento y acción revolucionarias. Montado en todos ellos, Luis Alberto Romero resaltó los desmadres que los revolucionarios hubiesen sido capaces de hacer en una hipotética toma del poder y los emparentó con los dictadores genocidas; en sus propios términos: "No es claro que el terrorismo de Estado haya sido peor que lo que hicieron las organizaciones armadas". ${ }^{2}$ La importancia de la inclusión de Romero en la indagación del pasado reciente reviste especial relevancia por su ubicación en el universo académico, aportando, más allá de sus controversiales opiniones políticas, una legitimación de una mirada condenatoria signada más por las creencias y urgencias politicas propias que por el profesionalismo del que debería hacer gala.

A mitad de camino, José Pablo Feinmann (1999), con un libro escasamente citado pero de enorme importancia por sus esfuerzos conceptuales, ciertamente malogrados, no dejaba de alertar sobre la dicotomía violencia/política, entendiendo la primera como una clara expresión de la negación de la segunda. En esta línea, la violencia es

2.La Nación, 20 de agosto de 2015. 
presentada como parte constitutiva del "mundo de la guerra", mientras que la política lo es de la negociación e, incluso, de la construcción de la democracia misma.

\section{II}

Como es sabido, el estudio y la reflexión en torno a la lucha armada caló hondo en el campo historiográfico, muy especialmente desde la crisis político-institucional del año 2001, cuando la radicalización de amplios sectores de la sociedad, traccionados por la convulsiva coyuntura, constituyó un aliciente de importancia para el mundo académico, que reencaminó su mirada y sujeto de estudios hacia la profundización de experiencias de masas, populares y revolucionarias recientes.

En dicho marco -en el que también tuvieron generosa incidencia experiencias continentales como la emergencia zapatista en 1994-surgieron con renovados bríos los estudios sobre el movimiento obrero, los movimientos por los derechos humanos y, de manera particular, sobre las organizaciones político-militares. El fenómeno, traducido en un auténtico boom editorial y la multiplicación de ponencias, tesis, seminarios, etc., dio cabida a una variedad destacable de trabajos, en la que destacan tres tendencias argumentativas, algunas de las cuales comparten ciertas características:

Enfoque organizacional. La primera refiere al predominio de una mirada organizacional, donde prevalece el sujeto organizacional propiamente dicho, aunque no como expresión particular de una realidad política, social y cultural de la sociedad argentina en una determinada coyuntura que, de alguna manera, promovió y estimuló su emergencia.

Estos estudios tienen una principal virtud: nos devuelven mucho de la "vida interna" de las OPM, revelada por documentos y testimonios de inmenso valor, pero padecen el limite de desgajarse de lo que Marx llamaba la "historia viva", es decir, tienen la propensión a historiar a las organizaciones de manera que la "situación politica nacional" es un mero marco de actuación reactivo y no un complejo multifactorial que interpeló y contribuyó a condicionar tácticas y estrategias que, anidadas en tradiciones y hechos históricos, fueron cobrando cuerpo al calor de diversas coyunturas políticas. Otro tanto sucede con el marco regional e internacional, donde las apelaciones reiteradas a cierto "espíritu de época", fundado en la influencia de las revoluciones cubana, argelina y vietnamita -tratadas como un todo homogéneo en sus características e incidencias en las autodenominadas vanguardias-, pareciera explicar y hasta prohijar las actuaciones de las OPM. Por lo general, responden a esta mirada las historias oficiales o paraoficiales. 
En este tipo de producciones son casi nulas o muy superficiales las referencias a la elaboración e implementación de las políticas concretas de las diversas organizaciones en los frentes de masas y muy particularmente en el sindical. En el caso de las OPM más importantes, como el PRT, no se ha profundizado sobre el desarrollo de los Comités de Base, numerosos en el cordón industrial de Zárate-Campana, y que terminaron constituyendo uno de los centros de la fracción del ERP 22 de Agosto, interpelado fuertemente por el peronismo. Lo mismo puede afirmarse del Movimiento Sindical de Base. En la espera de abordajes también se encuentran las numerosas publicaciones partidarias específicas para el movimiento obrero -entre ellas, los boletines para la IKA-Renault y El Zafrero para los peones rurales-, determinantes para poder descifrar influencias, penetraciones y representaciones ciertas en fábricas y sindicatos.

En cuanto a las OPM peronistas sucede algo similar: las historias organizacionales dicen poco de la JTP en sus múltiples regionales y también sobre sus publicaciones, como La Justa la tienen los laburantes, su órgano oficial. Y casi nada sobre los movimientos villeros, barriales, de inquilinos, etc. Es decir, esta perspectiva de estudios no ha sumado investigaciones que contribuyan a visualizar las relaciones entre las OPM y el movimiento social en general (y el obrero en particular), los avances concretos y las dificultades surgidas, y de qué manera éstas fueron pensadas y resueltas.

En buena medida, una de las limitaciones de la mirada organizacional la constituye la empatía de los autores con determinadas OPM, que genera, por un lado, una identificación acrítica frente al sujeto de estudio, con el abandono de todo intento de complejización en la investigación. El problema, por supuesto, no es la adscripción política e ideológica de los investigadores, sino la perversión acrítica que opera en contra de una investigación.

En los estudios de este tipo es dificil hallar una confrontación con las afirmaciones de los documentos citados, existiendo una identificación acrítica cuando se habla de "las masas", "la clase" y "la vanguardia", dando por ciertas "situaciones pre y revolucionarias" sin más, y haciendo referencia a una conflictividad social creciente, pero sin ahondar en elementos que fundamenten cambios sustanciales en la conciencia política de los protagonistas. Acompañan a estas caracterizaciones, siguiendo a pie juntillas las declaraciones de las propias OPM, afirmaciones sobredimensionadas acerca de la inserción de las mismas en el movimiento obrero, contabilizando "inserciones" por lo general sin especificaciones cuantitativas (cantidad de militantes y/o células en un establecimiento fabril, zona o región, distribución y círculos de lectura de la prensa, incidencia en los conflictos, delegados propios electos, etc.). La falta de 
cuestionamiento alcanza a considerar la mera inclusión de algún militante en una fábrica - por lo general solapado para evitar un prematuro despido- como "presencia" partidaria, lo que configura una apreciación impresionista que raya, en el mejor de los casos, con la ingenuidad.

Una de las más emblemáticas y reiteradas identificaciones acríticas refiere a la supuesta "ruptura" creciente de las masas con el gobierno peronista y con la burocracia sindical, que se corona en otra superficialidad altisonante referida al "agotamiento" de la experiencia peronista. Estas superficialidades eran moneda corriente en los años 70. Cuarenta años más tarde, no pocos investigadores las reiteran, optando por eludir cuestiones tan complejas como las expectativas de las masas en la coyuntura electoral, sus posicionamientos reformistas y aún conservadores, elementos que caracterizaron a amplios sectores de los trabajadores y son ignorados en estos trabajos.

Por supuesto, la postura acrítica no logra avanzar más allá de la legitimación y la justificación, a manera de lo analizado por Georges Haupt (1986) respecto de la historiografia obrera estalinista.

Enfoque culturalista. Una segunda tendencia es aquella que destaca como elemento predominante en el análisis de una organización su cultura política y las construcciones identitarias, con sus particulares discursos, rituales, prácticas, imaginarios y representaciones simbólicas.

En términos generales, se trata de indagar acerca de imaginarios y sistemas de creencias y valores de determinada organización, para hallar en los mismos las claves de su interpretación. La tentativa, tras las huellas de lo soterrado y no explícito, en buena medida marca un intento de superar lo que no pocos consideran -y con cierta razón- las desventuras de una historia marxista basada en el puro determinismo socioeconómico, con sus incapacidades de comprensión y explicación de comportamientos individuales y grupales que claman una mayor profundización. Aquella operación aparecía vedada por este dogmatismo extremo que, en algunas investigaciones, se intenta resolver con pontificaciones del tipo "ausencia de un auténtico partido revolucionario" que, como es sabido, para algunos marxistas es la piedra angular de la malaventura de todo proceso revolucionario.

Paradójicamente, la mayor limitación que suele exhibir la mirada culturalista lo constituye un deslizamiento ahistoricista, sosteniendo que sistemas de creencias y proyecciones imaginarias "no sólo determinan las prácticas políticas sino también otorgan un sentido a los actos de la organización" (Carnovale, 2011: 12). Este determinismo de nuevo tipo no hace más que confirmar los peligros de aquello que sentenció Perry Anderson (1996), cuando advertía que "una historia sin ideas se da la mano con las ideas sin historia". 
En efecto, resulta por lo menos sesgado conceptuar una organización según lo que piensa y dice de sí y para sí misma, sin ahondar en las tensiones emergentes en la relación con el conjunto de los sectores sociales y en particular con aquellos en los que pretende incidir, tensiones que suelen interpelar e incluso contrariar en acto a los imaginarios "oficiales". En palabras de Hobsbawm (1976), hay "divergencia entre la realidad de los caballeros medievales y el sueño de la caballería". Ese sensible pliego situado entre el imaginario subjetivo y la realidad, siempre fundadora de nuevas subjetividades, suele ser reservorio de elementos esclarecedores del desarrollo y prácticas de toda organización, develando sus riquezas y matices inexplorados, aunque dificilmente se tenga algún éxito en esto último si la dialéctica entre la vida real de los sujetos y las representaciones que éstas hacen de ella no constituye el corazón del análisis.

Desde esta perspectiva, poco ha contribuido el amontonamiento de imaginarios y subjetividades junto a una variedad de autores que legitiman sus emergencias. Así, con un poco de Paul Ricoeur y Alain Badiou por aquí, y de Georges Bataille y hasta Carl Schmitt por allá, entre otros, se puede convalidar el origen de los vistosos imaginarios de las OPM, pero la fórmula no basta para avanzar en la explicación y comprensión, en la arena histórica, de las complejidades de la práctica armada vernácula.

Uno de los más preciados y reiterados objetos de estudio de esta mirada lo constituye el análisis del imaginario sacrificial, que implica una particular relación con la muerte que, entendida como consagración del sacrificio, es siempre heroica. En otras palabras, el sacrificio y la muerte constituidos en objetos de deseo, generadores de una suerte de "seducción" que no puede sino desembocar en el desprecio por la vida, propia y ajena. Sus argumentos tienen sostén: ¿cómo ignorar consignas como "Patria o Muerte", "Perón o Muerte" y "A vencer o a morir por la Patria Socialista"? Ni hablar de aquella sentencia del Che, cuando dice: "En cualquier lugar que nos sorprenda la muerte, bienvenida sea...". Por lo demás, la referencia al sacrificio y muerte de los combatientes ha sido muy extendida en las guerrillas latinoamericanas y ha sido bien documentada (Melgar Bao, 2005).

Nadie que analice estas consignas y representaciones puede dudar de la presencia de un imaginario sacrificial, pero asignarlo como determinante de las prácticas de la militancia revolucionaria armada constituye un salto que ignora tradiciones e ideologías radicales que exceden largamente la cuestión.

Desde Marx y Engels en adelante, queda claro que toda politica es violenta y toda violencia es politica. Se podrá estar de acuerdo o no con esta interpretación, pero la misma ha establecido un piso ideológico 
fundante de una de las tradiciones politicas más sólidas de los revolucionarios. El PRT se enmarcó en este concepto. La revolución socialista, en el marco de la lucha de clases, implica una confrontación fatal entre las clases subalternas y las dirigentes, entre explotados y explotadores, como consagrara el Manifiesto comunista. La noción de revolución es, por sobre todas las cosas, una noción devastadora. La política revolucionaria socialista implica la destrucción del sistema capitalista y eso, en la fase crítica del enfrentamiento, morir y matar. No hay manera de analizar, comprender y explicar una organización revolucionaria-como el PRT-, sin entender dicha praxis.

Las OPM de origen peronista también, desde sus origenes, han hecho de la relación política/violencia un punto central, asumiendo como propias las tradiciones de acción directa que atraviesan la historia en general y la nacional en particular. La propia relación simbólica de Montoneros con sus homónimos del siglo XIX hace referencia a los alzados en armas; también la elección nominal "Fuerza Armada" utilizada por otras OPM, como las FAP y las FAR, habla por sí sola. Por otra parte, no está de más recordar que la consigna "la violencia de abajo no es violencia, sino justicia", lejos de ser una invención peronista, fue acuñada por el anarquismo y utilizada por el anarco-sindicalismo europeo de las décadas de 1920 y 1930, siendo oportunamente apropiada por la Resistencia Peronista y más tarde por el conjunto de las OPM.

La acción directa militar, "el matar y morir", pues, tiene raíces sólidas en la ideología revolucionaria y en la conciencia, la experiencia y la memoria colectiva nacional, incluido el radicalismo yrigoyenista que ha sabido exhibir una violencia militar extraordinaria desde finales del siglo XIX hasta bien entrado el siguiente. No es menor que el radicalismo brindara numerosos cuadros a las OPM, especialmente al PRT.

Puede hablarse largamente de la relación violencia/sacrifico en la constitución de las OPM, pero la emergencia de las mismas es, desde su concepción, una propuesta de violencia política tributaria de las experiencias e ideologias del movimiento obrero internacional y nacional, violencia declarada y jamás oculta.

Por otra parte, parece necesario resaltar que la subjetividad sacrificial no es exclusiva de tal o cual grupo, sino una construcción histórica que atraviesa a todas las épocas, movimientos sociales y clases. La historiografia de "la muerte" ha contribuido en parte a develar algunas de estas cuestiones (Chaunu, 1979; Ariès, 1983, 2009; Vovelle, 1985), como así también la de los movimientos milenaristas (Cohn, 1981) y prerrevolucionarios (Hobsbawm, 1968).

Ahora bien, como es sabido, la mirada "culturalista" suele destacar que el sacrificio militante conducía al martirologio, cuya mayor expresión implicaba "dar la vida", metáfora extrema tributaria de la 
ejemplaridad del Che, para quien la revolución lo implicaba todo; en sus palabras: "No hay vida fuera de ella" (Guevara, 1977). Abordado desde su excluyente mirada literal, abjura de sus concretos sentidos políticos en un determinado contexto histórico. Así, para Carnovale, "Dar la vida significaba ofrendarla" (2011: 195), en una suerte de redención glorificante. Ciertamente, la mayoría de las OPM de las décadas del 60 y 70 entendieron la muerte en combate de sus miembros como consagratorias de la virtud revolucionaria, pero es llamativa la distancia entre sus discursos y representaciones y las actuaciones concretas de los militantes. Y es en este pliego donde se verifica que "dar la vida" no significó abrazar la muerte, sino esforzarse sobradamente en pos de los objetivos de la organización. En este sentido, Pablo Pozzi acierta al señalar que los militantes no esperaban morir, sino triunfar. ¿Cómo se explica la vigencia de un mandato sacrificial con las operaciones que se suspenden por el grado de riesgo propio y de los transeúntes ocasionales? Sobran los testimonios certificando más operaciones suspendidas que realizadas por esta razón. Por otra parte, abundan los casos en los que en una operación de propaganda, que incluia la colocación de un artefacto explosivo en dependencias policiales, por ejemplo, iba acompañado por el aviso previo al destacamento y el alerta necesario en el barrio para evitar víctimas. Este extremo cuidado puesto en la planificación y ejecución de operaciones armadas fue una distinción superlativa de la mayor parte de las OPM. Las primeras FAL, por caso, serán conocidas como la "banda de los suizos", por su precisión relojera a la hora de actuar, lo que implicaba una limpieza de sangre absoluta; lo mismo cuenta para la GEL, cuya cuidadosa operatividad fue destacada por la propia Policia de Buenos Aires. ${ }^{3}$ Casi todas las organizaciones contaron con sus "ingenieros" para estructurar logísticas tan eficaces como seguras y las operaciones más audaces solian planificarse hasta en los más mínimos detalles y probables imponderables; algunas OPM, incluso, incorporaron como modalidad la realización de un simulacro en tiempo, lugar y con equipo completo, antes de realizar la operación planeada. También algunas estadísticas resultan contundentes: de un total de 5.300 hechos armados realizados por las OPM en el período mayo 1973 - marzo 1976, el 81,8\% no produjo ningún tipo de víctimas (Marín, 1984: 123). Ciertamente, conocemos irresponsabilidades graves por los costos humanos que significaron, pero muy lejos de constituir un rasgo hegemónico en la práctica armada; a propósito de esto, la historiografia especializada debería prestar atención a la cuestión y periodizarla, ya

3. Policía de la Provincia de Buenos Aires, "Comunicado de Prensa n 2102", Oficina de Prensa y Difusión, La Plata, 26 de noviembre de 1971. 
que la descomposición de la operatoria armada tiene un origen politico a clarificar, y no es obra de mandato sacrificial alguno.

Subalternizar la historicidad de una organización política a diversos imaginarios, tampoco ayuda a comprender las notables diferencias entre las organizaciones que no emprendieron las mismas prácticas, aunque sí compartían la misma "cultura política" y variados imaginarios acerca de la praxis revolucionaria. La cuestión cobra relevancia en tanto contribuye a entender las OPM no como un todo monolitico ya determinado, sino como la dinámica expresión de diversos sectores sociales organizados alrededor de identificaciones ideológicas, políticas, sociales y culturales, con sus diversas tácticas y estrategias de intervención en un determinado contexto histórico.

La propia praxis armada refleja este universo de diferencias y comportamientos que no desmiente la existencia de imaginarios particulares, pero sí su preeminencia determinante en las construcciones organizacionales.

Ya en 1968, durante el congreso del Peronismo Revolucionario, la acción armada se consolidó como táctica, mas los criterios políticos de cómo y cuándo ponerla en práctica chocaron ostentosamente. El sector liderado por Haroldo Logiurato apostaba a la ejemplaridad guerrillera como accionar previo a cualquier alzamiento generalizado, mientras que el representado por Gustavo Rearte rechazaba esto, entendiendo la acción armada como coronación de la madurez de un movimiento social. En 1970-1971, un sector de Montoneros conformado por los encarcelados de La Calera, producirá una sustancial crítica a la operatoria armada en el Documento verde, plataforma de lo que luego tomará cuerpo organizacional en la Columna Sabino Navarro. Montoneros mismo se estructurará como "partido armado" recién en 1975, con críticas internas de envergadura como la protagonizada por el propio Rodolfo Walsh (Salas, 2006). Por su parte, los guevarianos argentinos constituyeron organizaciones politicas, sociales y militares, con un despliegue de fuerzas sobre territorio sindical, barrial, cultural y estudiantil impensable para el foquismo, tales los casos del PRT, el GOR y la OCPO. Las organizaciones que sólo construyeron guerrillas foquistas urbanas desaparecieron tempranamente.

La operatoria armada, pues, tomó disímiles caminos: en su V Congreso (1970), el PRT dará vida al brazo armado partidario, el ERP, mientras que el GOR, organización naciente de la crisis de aquel congreso, mantendrá una línea de intervención en los movimientos sociales enfatizando su autodefensa, posición cercana a la de varias pequeñas organizaciones que en 1974 motorizarán los Piquetes Obreros Armados (POA) durante el conflicto de Villa Constitución; un año más tarde, la OCPO, principal animadora de los POA, conformarán las Brigadas 
Rojas. La cuestión repercutió también en organizaciones menores que quedaron sumidas en debates internos con notables diferencias, como en el pequeño MR Che y en algunas columnas de las FAL. Sumemos, además, a organizaciones como el Partido Revolucionario de los Obreros Argentinos (PROA), que expresó su rechazo a la confrontación armada de grupos vanguardistas en tanto opuesta a las tradiciones colectivas del movimiento obrero; su crítica alcanzaba a la figura del combatiente en tanto héroe y ser excepcional, caracterización que levantaban varias organizaciones y ellos rechazaron enfáticamente. ${ }^{4}$

Estas notables diferencias en organizaciones que compartían la misma cultura política e hicieron propio el "dar la vida" por sus ideales, se ratifican a la hora de analizar otros imaginarios y mandatos que implicaron, supuestamente, el sentido mayor de la militancia setentista.

Es sabido que en algunas OPM circularon documentos del tipo normativo relacionados con la moral revolucionaria que debía reglar la vida de los militantes y combatientes, un conjunto de valores del revolucionario arquetípico con pretensiones de atentar contra el individualismo pequeñoburgués, pecado original que acunaba todos los males. Las normativas, no siempre escritas, debian guiar al militante hacia su conversión ejemplar, y su ejemplo, en una pura práctica pedagógica, convertirse en inspirador para el colectivo y, por supuesto, para "las masas".

La cuestión tenía como tópico central la voluntad, entendida como una herramienta sin par para la concreción de los postulados revolucionarios. La voluntad debía ser férrea y, tal como lo señala de manera transparente un documento de la GEL, "debe ser educada". ${ }^{5}$ No resulta extraño entonces que comenzaran a proliferar escritos "regulatorios" de la vida militante, con la intención de articular el funcionamiento colectivo de las organizaciones. Regulación que, en definitiva, reproducía lo que sucedia en el conjunto de la sociedad y el Estado en sus vastas mediaciones, en todas las épocas y latitudes.

La GEL y las FAL se adentraron tempranamente en estas elaboraciones, que estuvieron lejos de llevarse a cabo sin grandes tensiones internas, documentadas en sus informes y debates que llegaron a alcanzar ribetes cismáticos, cuestión nada menor que puede contribuir a poner en discusión la capacidad argumentativa de la mirada culturalista.

El paradigma de estas normas es el folleto "Moral y proletarización" del PRT (1972), cuya incidencia en la vida interna de la organización ha sido sobrevaluada por quienes le han dado mayor trascendencia

4. Militancia para la construcción del Partido Revolucionario de los Obreros Argentinos, $\mathrm{n}^{\circ} 1$, diciembre de 1975 - enero de 1976.

5. "Mensaje de la Dirección", 11 de febrero de 1971. 
y verosimilitud a lo escrito que a lo actuado o, por lo menos, no han analizado la contradictoria espesura existente entre uno y otro sentido.

En el PRT y en otras organizaciones se establecieron criterios morales acerca de la pareja, la infidelidad, las prácticas sexuales, etc., dirigidos, supuestamente, a prefigurar a los militantes como arquetipos del hombre nuevo. Ciertamente, en nombre de dichas normas, hubo expresiones de una moralina exacerbada en un intento de modelación autoritaria, incluidas imputaciones por violación de estas normas y hasta juicios con sentencia formalmente declarada. Pero concluir que estas normas, basadas en imaginarios de pureza revolucionaria, constituyeron un sustento determinante en la construcción de las organizaciones resulta exagerado en virtud de la multiplicación de casos que lo desmiente. Rolo Diez certifica esto último de manera palmaria destacando, incluso, que si el partido hubiese condenado cada caso de "moralidad pequeñoburguesa", la dirección nacional perretiana corría el riesgo de "convertirse en un desierto" (Diez, 2010: 40). El imaginado manantial de integridad proletaria poco pudo contra las actuaciones concretas: como era de esperar, el propio partido desaconsejó la lectura del problemático folleto en 1974, y abjuró de procesos moralizantes. Esta "flexibilidad" intencional, forzada por la realidad, resulta un notable indicativo de las tensiones y contradicciones constitutivas de la organización, atentando contra cualquier definición estereotipada acerca de su construcción.

Otro ejemplo lo reporta la constitución de una familia en el universo combatiente. En algunas organizaciones se entendía la conformación de una familia con hijos como un impedimento a la "entrega total" de los militantes: la revolución implicaba el involucramiento y compromiso absoluto, lo que chocaba con cualquier tipo de atención a los tipos de construcción personal que atentara contra ello. No conozco documento alguno que lo señale, pero era un secreto a voces. Siendo tal el mandato: ¿cómo se entiende que estos preceptos fueran lisa y llanamente ignorados? Una muestra de ello son los cientos de niños apropiados, más de 500, además de los niños que lograron, con o sin sus padres militantes, evitar la represión.

Sostenida por unas cuantas entrevistas y algunos documentos, la presencia de una intervención de la organización en la modelación de la vida privada de los militantes no puede ignorar otros tantos testimonios que destacan cómo esa intervención era resistida y hasta soberanamente ignorada e, incluso, burlada, sin que la organización se viera mayormente afectada en su operatividad cotidiana. ¿Cómo debe entenderse la construcción de una organización con semejantes contradicciones internas? ¿Es verosimil acreditar a los imaginarios identitarios un rol determinante sin contemplar condicionamientos y variaciones?

Algo similar puede destacarse respecto de la política de "proletariza- 
ción". Al analizarla en el PRT, Carnovale señala que la misma "constituía otra de las formas que asumió el mandato partidario del sacrificio." (Carnovale, 2011: 246). Sin duda que la proletarización contuvo un componente sacrificial referenciado, en parte, sobre un proletariado sacralizado e idealizado, mirada que diversos sectores de la izquierda y de las corrientes que se reclamaban del movimiento obrero y popular hicieron propia. Pero otorgarle a dicha práctica tal soporte vital no constituye más que un recorte que menoscaba principios ideológicos y estrategias y tácticas que, con sus claros y oscuros, intentaron, también por esta vía, una construcción clasista de horizontes revolucionarios.

¿Fue provechosa la experiencia de proletarización?, ¿contribuyó a extender las redes sociales y a la penetración de las organizaciones en el movimiento obrero?, ¿resultó una táctica exitosa para incidir en el desarrollo de las aspiraciones y objetivos revolucionarios?, ¿o acaso sumió a las organizaciones en un retroceso y en la frustración de sus militantes? Ciertamente, a Carnovale la cuestión no la inquieta: "no me he interesado tanto por los ajustes o desajustes entre su línea política y la realidad histórica" (2011: 21), señalando, en cambio, su intención de "reconstruir la trama de ideas, creencias, representaciones y valores que fueron determinando su accionar" (2011: 22). Esta curiosa tentativa de evaluar determinantes de un accionar por fuera de la realidad histórica no contribuye a explicar los sentidos de la proletarización como praxis política, cuyos resultados concretos sí pueden pensarse como determinantes para el accionar y la construcción de la organización.

En efecto, para el PRT la proletarización resultó de enorme importancia en la estructuración de núcleos combativos en numerosas empresas, fábricas, talleres y barriadas, muchos de los cuales aportaron delegados, referentes obreros y simpatizantes que constituyeron colaboradores esenciales para la difusión y desarrollo de la organización, incluso aún en situaciones de seguridad extremadamente frágil. De hecho, la proletarización fue esencial en la constitución de círculos obreros de lectura de las prensas partidarias, pieza de enorme importancia para el apoyo del trabajo en las fábricas que la mirada culturalista no ha incorporado a su análisis. A propósito de esto, un informe de Inteligencia del Ejército reproduce información de extraordinario valor, ${ }^{6}$ donde se puede leer el relevamiento que el PRT realizó de su red de círculos de lectura en varias fábricas del país, donde la actuación de los que "marcharon hacia el pueblo" fue central. Contar, por ejemplo, con 17 lectores en INDIEL, 12 en Kaiser, 20 en Tamet, 12 en Fabril Financiera, 6 en General Motors y varios más en Propulsora y Astilleros, no era tocar el cielo con las

6. Informe Especial Mensual de Inteligencia $n^{\circ}$ 4/76. Estrictamente Secreto y Confidencial, G.T. 1, Eq.1/2 "Detección de la reunión del Comité Central del PRT-ERP”. 
manos, pero en los inicios de la dictadura se le parecía bastante. En vista de estos logros obtenidos -testimonios diversos señalan que en el período inmediatamente anterior estos círculos de lectura eran mucho más vastos y nutridos-, el partido propuso acentuar la proletarización de sus militantes.

En definitiva, no se trata de negar la presencia e importancia que cobró en las OPM el discurso sacrificial como así también los diversos imaginarios propios, sino de evaluar su incidencia en un corpus doctrinario y experimental propio de la lucha de clases, analizando críticamente su desarrollo e influencia concreta en relación con los movimientos sociales, que por lejos fue la prioridad militante de la mayoria de las OPM de los más diversos orígenes ideológicos. Desde esta perspectiva, la identidad medular de estas organizaciones estuvo dada por sus presupuestos ideológicos y programáticos partidarios. La presencia de imaginarios y subjetividades aglutinadoras constituyeron un elemento cierto pero complementario, colectivamente enmarcado en la entrega mayor por los ideales fuerza de las organizaciones; en algunos casos, incluso, el rol aglutinador de los imaginarios "oficiales" fue por completo secundario, en tanto fueron soberanamente ignorados.

Sociología del conflicto social. Finalmente, la tercera mirada, representada por el grupo que anima Inés Izaguirre y que continúa lo trabajado por Marin, estudia las OPM desde una perspectiva de lucha de clases en un pasaje crítico de lucha armada (Izaguirre, 2009).

Generalizando, el grupo establece la existencia de una guerra civil que no respondió a la tipología de "clase contra clase", pero sí en la que la violencia fue el instrumento de las distintas fracciones sociales en lucha. Particularmente en el período marzo 1973-marzo 1976 visualizan una paridad de conflictos obreros (8.400) y de hechos armados (8.509), de lo que se desprende como conclusión que "es dificil negar la existencia de una guerra civil con semejantes cifras" (Izaguirre, 2009: 261).

Todo esto en un marco general abierto en el Cordobazo donde se combina la lucha obrera y de masas en las calles con ánimo insurreccional (Izaguirre, 2009: 83) y el surgimiento de OPM en disputa por la hegemonía de las Fuerzas Armadas del Estado. Ese proceso inaugura un período de guerra civil que clausura la dictadura de 1976.

Se observa una consideración sobredimensionada de lo que es un conflicto social, politico y un hecho armado. Por un lado, la masiva lucha sindical contra el Pacto Social, en un marco inflacionario desatado, ha demostrado con creces hasta dónde los trabajadores se han movilizado en defensa de sus intereses, pero resulta poco convincente para considerar el desarrollo de su conciencia politica. No hay suficientes indicios que indiquen que tras lograr las reivindicaciones económicas, por ejemplo, 
los trabajadores anhelaran disputar la hegemonía al peronismo que ellos mismos habian aguardado durante 18 años y apoyado masivamente en las elecciones del 11 de marzo de 1973.

Por otro lado, tampoco queda clara cuál es la relación entre un hecho armado y el nivel de conciencia de los trabajadores. De los 8.509 hechos armados: ¿cuántos fueron desarmes u operaciones de aprovisionamiento logístico, de los que apenas se enteró el responsable político de una célula y a los sumo unas pocas personas más? Es sabido que las OPM han mantenido una visión sobredimensionada de sus operaciones armadas, considerando buena parte de las mismas sin mayor distinción que la de tratarse de una avanzada del pueblo. Es menester especificar esto ya que relacionar toda operación armada con la conflictividad social y la conciencia politica pareciera forzado y poco serio.

Ciertamente, la mirada sobredimensionada alcanza a la caracterización del período, al que se le otorga espesura de "guerra revolucionaria" o "escalada revolucionaria", además de destacar algunas operaciones armadas como "grandes batallas" en los ejemplos de Azul, Formosa y Monte Chingolo (Nievas, 2009: 119-121), operaciones de indudable importancia y complejidad, pero que en la observación de los historiadores deberian tener una evaluación independiente de la subjetividad de los propios actores que, efectivamente, las vivieron como tales.

De alguna manera, lo mismo cuenta al caracterizar el estado de guerra: que las Fuerzas Armadas y de Seguridad, como así varias OPM, lo creyeran, no suma argumentos que concluyan que las masas, en su conflictividad social, lo aceptara y compartiera en sus propios términos. Ciertamente, se apoyan en la premisa de que los trabajadores no desaprobaron el accionar de las organizaciones revolucionarias y, en cambio, dieron la espalda a los sectores contrarrevolucionarios, pero no queda claro cuál fue la influencia de los enfrentamientos armados en la conciencia de los trabajadores. En la fábrica de pinturas Miluz, por ejemplo, el ERP ejecutó a dos directivos de la fábrica luego de que fueran asesinados dos delegados de Política Obrera, tras lo cual, finalmente, la Triple A asesinó al delegado que los sucedió: ¿Cómo se leyó esta intervención en planta? ¿Cuál fue la conciencia que se viralizó en las fábricas de la zona? ¿La del apoyo a las OPM? ¿Cómo debe entenderse que en uno de los velatorios de los delegados asesinados varios obreros de la fábrica tiraron la bandera roja que se había depositado sobre el féretro?

Poco aporta alentar conclusiones que no están respaldadas por estudios acerca del enraizamiento de las OPM en fábricas y barriadas y la percepción de los trabajadores sobre las organizaciones revolucionarias. De hecho, contradiciendo buena parte de sus argumentos, señalan que las masas no quebraron, "en líneas generales, el espectro de su con- 
ciencia burguesa" (Nievas, 2009: 120), y que ningún desplazamiento de gobernadores afines a Montoneros fue resistido por las masas: "la actitud generalizada frente a los golpes de Estado [provinciales] fue la indiferencia" (Bonavena, 2009: 235).

Por el contrario, muestran la intencionalidad saludable de demostrar la relación entre los conflictos sociales y las intervenciones de las OPM, pero ésta se lesiona cuando se fuerzan conclusiones que sólo llevan agua al molino de sus planteos.

Ciertamente hubo avances en el análisis sobre la articulación de las OPM y los movimientos sociales, pero por lo general provenientes de otras miradas: Federico Lorenz (2006) con su trabajo sobre los astilleros es un buen ejemplo; también los avances de Löbbe (2006), y de Pozzi y Schneider (2000) sobre las Coordinadoras fabriles.

\section{III}

A más de cinco décadas de la emergencia guerrillera y a más de cuatro de la última dictadura cívico-militar, aún carecemos de una historia global de la guerrilla argentina con una mirada integradora. Tampoco se cuenta con un mapa de las OPM nacional y regional y, de manera más o menos completa de su inmenso acervo documental. ${ }^{7}$ Aún no existen historias de los intentos organizacionales de dimensión continental, como la Junta Coordinadora Revolucionaria (JCR), y es prácticamente nulo el estudio de las relaciones internacionales que las OPM establecieron.

Evidentemente, un enorme problema a resolver es la reconstrucción de una historia que tiene de todo, menos homogeneidad. Definitivamente no se puede hablar seriamente de la guerrilla argentina como un todo monolítico. Hay diferencias sustantivas entre las organizaciones tanto de origen marxista como peronista. Hay organizaciones con frentes de masas y publicaciones regionales y nacionales (incluso diarios como El Mundo y Noticias) y hay OPM que carecen de unos y otros. También dentro de una misma organización hay etapas diferenciadas, en el marco de una situación política y social nacional absolutamente cambiante en un período no mayor de siete años.

Tal complejidad debe dar cuenta, además, de una indispensable búsqueda de nuevas fuentes documentales que, hasta el momento, no han sido utilizadas por los historiadores o lo han sido de manera insu-

7. No pretendo soslayar los ingentes esfuerzos de Roberto Bascheti y Daniel de Santis, quienes recuperaron y dieron a difusión centenares de documentos. Tampoco la tarea del Topo Blindado que ya lleva publicado en su sitio web más de 3.000 documentos. Aún así, es cuantiosa la cantidad de ejemplares de prensa, boletines internos, folletos, volantes, conferencias de prensa, afiches, grabaciones, etc., que faltan recuperarse y darse a conocer. 
ficiente, como las fuentes judiciales y las militares, muy especialmente los partes de Inteligencia que suelen aportar elementos novedosos de análisis propios, que no deben ser subestimados, y documentos internos secuestrados a las OPM, como registros de operaciones no divulgadas, datos de las estructuras internas, alcance de penetración en diversos frentes, publicaciones especiales para diversos ámbitos de actuación, etc.

Las tentativas de historiar las actuaciones de las diversas OPM como reconstrucciones organizacionales, manipulando acontecimientos a conveniencia y reproduciendo las imágenes recreadas por ellas mismas han dado tan magros resultados como las búsquedas de identidades e imaginarios descontextualizados y carentes de confrontación con las contradictorias realidades de las propias OPM en particular y del movimiento social en general. Así las cosas, los avances de los que se puede hablar tienen más que ver con la definición de los problemas a dilucidar que con los resultados alcanzados. El camino comienza a desbrozarse, lo que no es poco.

Todo esto indica que la historia de la guerrilla argentina, en cualquiera de sus manifestaciones e independientemente de las dimensiones que haya cobrado tal o cual organización, no puede ser trabajada seriamente si es desligada del proceso histórico nacional, de las tradiciones y cultura del conjunto de la sociedad frente al conflicto social, sus diversas representaciones y, por supuesto, las luchas desarrolladas en los más diversos planos. La historia de la guerrilla, en suma, desgajada de la "historia viva" se convierte en un mero objeto curioso, casi en un anecdotario proveedor, según se interprete, de pesadillas o epopeyas, al alcance de la mano para elaborar artículos, libros, tesis e intervenciones más o menos prolijas que mayormente sólo cierran en sí mismas.

Pareciera oportuno volver a hacer hincapié en la ponderada (pero poco practicada) sentencia de Gramsci: "la historia de un partido no significa otra cosa que escribir la historia general de un país desde un punto de vista monográfico, para subrayar un aspecto característico".

El gran desafio que sigue planteado es una historia que no escamotee ninguna crítica, ninguna perspectiva de análisis, ninguna apertura que complejice y expanda la historia social de un fenómeno que continúa interpelando a la historia y a la sociedad argentina.

\section{Bibliografia}

AA.VV. (2009), Organización Comunista Poder Obrero: una aproximación al socialismo revolucionario en los 70, Buenos Aires: A Vencer.

Acuña, Carlos Manuel (2000), Por amor al odio. La tragedia de la subversión, Buenos Aires: Del Pórtico.

Alcoba, Laura (2008), La casa de los conejos, Buenos Aires: Edhasa. 
Anderson, Perry (1996), Los fines de la historia, Barcelona: Anagrama.

Andújar, Andrea (2009), "El amor en tiempos de revolución: los vínculos de pareja de la militancia de los 70. Batallas, telenovelas y rock and roll”, en A. Andújar (comp.), De minifaldas, militancias y revoluciones, Buenos Aires: Luxemburg.

Ariès, Philippe (1983), El hombre ante la muerte, Madrid: Taurus.

- (2009), Historia de la muerte en Occidente. Desde la Edad Media hasta nuestros dias, Madrid: Acantilado.

Ávalos, Daniel (2005), La guerrilla del Che y Masetti en Salta, 1964. Ideología y Mito en el EGP, Córdoba: La Intemperie.

Bonavena, Pablo (2009), "Guerra contra el campo popular en los 70", en Inés Izaguirre y colaboradores, ob. cit.

Brocato, Carlos Alberto (1985), La Argentina que quisieron, Buenos Aires: Sudamericana.

Bufano, Sergio (2004), "La vida plena", en Lucha Armada, n 1.

- (2007), "La guerrilla argentina. El final de una épica impura", en Lucha Armada, $\mathrm{n}^{\circ} 8$.

Campione, Daniel (1996), "Los comunistas argentinos. Bases para reconstruir su historia", Periferias, $\mathrm{n}^{\circ} 1$, Buenos Aires.

- (2005), "Hacia la convergencia cívico-militar. El Partido Comunista 19551976", Herramienta, n 29, Buenos Aires.

- (2007), "El Partido Comunista: Apuntes sobre su trayectoria", disponible en www.alainet.org.

Campos, Esteban (2016), Cristianismo y Revolución. El origen de Montoneros, Buenos Aires: Edhasa.

Carnovale, Vera (2011), Los combatientes. Historia del PRT, Buenos Aires: Siglo XXI.

Carra, Juan (2008), "El PRT-ERP en la ciudad de Mar del Plata", en Lucha Armada, $\mathrm{n}^{\circ} 11$.

Casola, Natalia (2015), El PC argentino y la dictadura militar, Buenos Aires: Imago Mundi.

Castro, Dardo y Juan Iturbure (2004), "Organización Comunista Poder Obrero", Lucha Armada, no 1, Buenos Aires.

Caviasca, Guillermo (2006), "Arturo Lewinger y los orígenes de las FAR", Lucha Armada, $\mathrm{n}^{\circ}$ 6, Buenos Aires.

- (2013), PRT-ERP y Montoneros, la guerrilla argentina en una encrucijada, La Plata: De la Campana.

Celentano, Adrián (2005), "Maoísmo y lucha armada: el PCML", Lucha Armada, $\mathrm{n}^{\circ} 4$, Buenos Aires.

Chaunu, Pierre (1979), Memoria de la eternidad, Madrid: Rialp.

Cohn, Norman (1981), En pos del milenio, Madrid: Alianza.

Cormick, Federico (2012), Fracción Roja. Debate y ruptura en el PRT-ERP, Buenos Aires: El Topo Blindado.

- (2015), "Apuntes sobre la Organización Comunista Poder Obrero", Cuadernos de Marte, año 6, $\mathrm{n}^{\circ}$ 8, Buenos Aires. 
Cortina Orero, Eudald (2011), Grupo Obrero Revolucionario. Autodefensa obrera y guerrilla, Buenos Aires: El Topo Blindado.

Diez, Rolo (2010), El mejor y el peor de los tiempos. Cómo destruyeron al PRT-ERP, Buenos Aires: Nuestra América.

Duhalde, Eduardo Luis y Eduardo Pérez (2002), De Taco Ralo a la Alternativa Independiente, Tomo I: Las FAP, La Plata: De la Campana.

Feinmann, José Pablo (1999), La sangre derramada. Ensayo sobre la violencia politica, Buenos Aires: Ariel.

Gillespie, Richard (1987), Montoneros. Soldados de Perón, Buenos Aires: Grijalbo.

Giussani, Pablo (1984), Montoneros, la soberbia armada, Buenos Aires: Sudamericana.

González Canosa, Mora (2012), "Las Fuerzas Armadas Revolucionarias. Orígenes y desarrollo de una particular conjunción entre marxismo, peronismo y lucha armada (1960-1973)", tesis doctoral, Universidad Nacional de La Plata.

Grenat, Stella (2010), Una espada sin cabeza: las FAL y la construcción del partido revolucionario en los 70, Buenos Aires: RyR.

Guevara, Ernesto (1977), "El socialismo y el hombre en Cuba", Escritos y discursos, tomo 9, La Habana: Ciencias Sociales.

Haupt, Georges (1986), El historiador y el movimiento social, Madrid, Siglo XXI.

Hendler, Ariel (2010), La guerrilla invisible. Historia de las Fuerzas Argentinas de Liberación (FAL), Buenos Aires: Vergara.

Hobsbawm, Eric (1968), Rebeldes primitivos, Barcelona: Ariel.

- (1976), Bandidos, Barcelona: Ariel.

Izaguirre, Inés y colaboradores (2009), Lucha de clases, guerra civil y genocidio en la Argentina. 1973-1983, Buenos Aires: Eudeba.

Lanusse, Lucas (2007), Cristo revolucionario. La Iglesia militante, Buenos Aires: Vergara.

Leis, Héctor Ricardo (2013), Un testamento de los años 70. Terrorismo, politica $y$ verdad en Argentina, Buenos Aires: Katz.

Löbbe, Héctor (2006), Clase obrera e izquierda en la Coordinadora Interfabril de Zona Norte del Gran Buenos Aires (1975-1976), Buenos Aires: RyR.

Lorenz, Federico (2006), Los zapatos de Carlito, Buenos Aires: Norma.

Luna, Gómez, Verdú y Berenzan (2007), "La Juventud Peronista en Luján", Lucha Armada, ${ }^{\circ} 8$.

Luvecce, Cecilia (1993), Las Fuerzas Armadas Peronistas y el Peronismo de Base, Buenos Aires: CEAL.

Mangiantini, Martín (2014), El trotskismo y el debate en torno a la lucha armada. Moreno, Santucho y la ruptura del PRT, Buenos Aires: El Topo Blindado.

Marin, Juan Carlos (1984), Los hechos amados: un ejercicio posible, Buenos Aires: CICSO. 
Martínez, Paola (2009), Género, politica y revolución en los años setenta. Las mujeres del PRT-ERP, Buenos Aires: Imago Mundi.

Massot, Vicente (2011), Matar y morir, Buenos Aires: El Ateneo.

- (2013), El cielo por asalto: ERP, Montoneros y las razones de la lucha armada, Buenos Aires: El Ateneo.

Melgar Bao, Ricardo (2005), "La dialéctica cultural del combate: morir, matar y renacer en la cultura guerrillera latinoamericana", Lucha Armada, $\mathrm{n}^{\circ}$ 4, Buenos Aires.

Morello, Gustavo (2003), Cristianismo y Revolución: los orígenes intelectuales de la guerrilla argentina, Córdoba: Universidad Católica de Córdoba.

Nadra, Alberto (2012), Secretos en rojo, un militante entre dos siglos, Buenos Aires: Corregidor.

Nicanoff, Sergio y Axel Castellano (2006), Las primeras experiencias guerrilleras en la Argentina, Buenos Aires: CCC.

Nievas, Flabián (2009), "Del Devotazo a Ezeiza. Guerra de posiciones en junio de 1973", en Inés Izaguirre y colaboradores, ob. cit.

Noguera, Ana (2013), "La participación de las mujeres en la lucha armada. Córdoba, Argentina, 1970-1973”, en Taller, vol. 2, n 2.

Oberti, Alejandra (2015), Las revolucionarias. Militancia, vida cotidiana y afectividad en los setenta, Buenos Aires: Edhasa.

Pascuali, Laura (2007), "Memorias y experiencias en las y los militantes de la guerrilla marxista. Un abordaje desde la historia social en el Gran Rosario, 1969-1976", tesis doctoral.

Pozzi, Pablo y Alejandro Schneider (2000), Los setentistas. Izquierda y clase obrera, 1969-1976, Buenos Aires: Eudeba.

Reato, Ceferino (2013), Viva la sangre, Buenos Aires: Sudamericana.

Robles, Horacio (2011), "Los barrios montoneros: una aproximación a las unidades básicas y la militancia de la JP articulada con Montoneros en la ciudad de La Plata (1972-1974)", en Los trabajos y los dias, n 3.

Rojas, Guillermo (2001), Años de terror y pólvora, Buenos Aires: Santiago Apóstol.

Rot, Gabriel (2000), Los orígenes perdidos de la guerrilla argentina. Jorge Ricardo Masetti y el EGP, Buenos Aires: El Cielo por Asalto. Edición corregida y aumentada, Buenos Aires: Waldhuter, 2010.

- (2003-2004), "Notas para una historia de la lucha armada en la Argentina. Las FAL", en Politicas de la Memoria, n 4.

- (2006), "El Partido Comunista y la lucha armada", Lucha Armada, no 7 , Buenos Aires.

Rot, Gabriel y Esteban Campos (2010), La Guerrilla del Ejército Libertador. Vicisitudes politicas de una guerrilla urbana, Buenos Aires: El Topo Blindado.

Salas, Ernesto (2003), Uturuncos. El origen de la guerrilla peronista, Buenos Aires, Biblos.

- (2006), "El debate entre Walsh y la conducción montonera”, Lucha Armada, $\mathrm{n}^{\circ} 5$, Buenos Aires. 
Salcedo, Javier (2011), Los Montoneros del barrio, Buenos Aires: Eduntref. Vezzetti, Hugo (2009), Sobre la violencia revolucionaria: memorias y olvidos, Buenos Aires: Siglo XXI.

Viano, Cristina (2011), "Pinceladas sobre las relaciones de género en la nueva izquierda peronista de los primeros años 70", en Temas de Mujeres, Tucumán, $\mathrm{n}^{\circ} 7$

Vovelle, Michel (1985), Ideologias y mentalidades, Barcelona: Ariel.

Weisz, Eduardo (2005), "El ERP 22 de Agosto: una fracción pro-Cámpora" en Lucha Armada, $\mathrm{n}^{\circ} 2$.

Yofre, Juan Bautista (2006), Fuimos todos, Buenos Aires: Sudamericana.

- (2007), Nadie fue, Buenos Aires: Sudamericana.

- (2009), Volver a matar, Buenos Aires: Sudamericana.

- (2010), El escarmiento, Buenos Aires: Sudamericana.

- (2014), Fue Cuba, Buenos Aires: Sudamericana.

Título: An evaluation of the studies on Argentine Political-Military Organizations

Resumen: El presente ensayo analiza el amplio universo de las producciones historiográficas alrededor de la violencia política en los años 70, la lucha armada como estrategia revolucionaria y el derrotero de aquellas organizaciones simultáneamente políticas y militares (OPM). Se abordan las líneas de análisis más destacadas y, en razón de ello, los vacíos historiográficos existentes.

Palabras clave: organizaciones político-militares - lucha armada - historiografia

Abstract: This paper analyzes the historiographical production about political violence in the seventies, the strategy of armed struggle and the course of the same political and military organizations (OPM). The most important writings are analyzed as well as outstanding themes.

Keynotes: political-military organizations - armed struggle - historiography

Recepción: 6 de junio de 2016. Aprobación: 16 de agosto de 2016 . 